\title{
CASP8 and FADD-Like Apoptosis Regulator Isoform 2
}

National Cancer Institute

\section{Source}

National Cancer Institute. CASP8 and FADD-Like Apoptosis Regulator Isoform 2. NCI

Thesaurus. Code C112064.

CASP8 and FADD-like apoptosis regulator isoform 2 (221 aa, $\sim 25 \mathrm{kDa}$ ) is encoded by the human CFLAR gene. This protein is involved in the regulation of caspase-dependent apoptosis. 